\title{
Genital inflammation, immune activation and risk of sexual HIV acquisition
}

\author{
Jo-Ann S. Passmore ${ }^{\mathrm{a}, \mathrm{b}, \mathrm{d}}$, Heather B. Jaspan ${ }^{\mathrm{a}, \mathrm{c}}$, and Lindi Masson ${ }^{\mathrm{a}, \mathrm{b}}$
}

\begin{abstract}
Purpose of review
Women who have genital inflammation are at increased risk of sexual HIV infection. The purpose of this review is to evaluate the mechanisms for this relationship, causes of genital inflammation, and strategies to manage this condition.

Recent findings

We have recently shown in a cohort of South African women that HIV seroconversion was associated with persistently raised genital inflammatory cytokines (including MIP-1 $\alpha$, MIP-1 $\beta$, and IP-10). Elevated inflammatory cytokine concentrations may facilitate HIV infection by recruiting and activating HIV target cells and disrupting the mucosal epithelial barrier. Bacterial vaginosis and sexually transmitted infections (STIs), which are predominantly asymptomatic in women, cause lower genital tract inflammation and increased HIV acquisition risk. In Africa, where syndromic management of STIs and bacterial vaginosis is standard-of-care, the substantial burden of asymptomatic infections has likely contributed to high-HIV incidence rates.
\end{abstract}

\section{Summary}

A genital inflammatory profile contributes to the high risk of HIV acquisition in African women. STIs and bacterial vaginosis are poorly managed in Africa and other developing nations and as such remain major drivers of persistent genital inflammation and HIV acquisition among these women.

\section{Keywords}

cytokines, genital tract, HIV risk, inflammation, T-cell activation

\section{INTRODUCTION}

Young women in sub-Saharan Africa are disproportionately affected by HIV, with infection risk of up to eight-fold higher than in men of the same age [1]. Despite new HIV infections dropping from 3.4 million in 2001 to 2.0 million globally in 2014 [2], continued transmission in young women is one of the greatest challenges preventing an AIDS-free generation [3]. Susceptibility to HIV infection varies considerably from person-to-person, with some women remaining uninfected despite repeated exposure [4]. Bacterial vaginosis and sexually transmitted infections (STIs) [5-8], as well as other biological factors, have been shown to impact the risk of young women acquiring HIV. Genital inflammation underlies many of these risk factors, providing a unifying mechanism driving risk [8,9"',10"'].

\section{HIV RISK AND GENITAL INFLAMMATION}

Inflammation in the female genital tract, regardless of the cause, creates an environment that favors HIV replication and establishment of a productive infection. Women with elevated concentrations of proinflammatory cytokines, including macrophage inflammatory protein (MIP)- $1 \alpha$, MIP-1 $\beta$ and IP-10, in their genital tracts were found to be at increased risk of HIV acquisition [9"']. Interferon gammainduced protein 10 (IP-10) MIP-1 $\alpha$, and MIP-1 $\beta$ are chemotactic for HIV target cells, including $\mathrm{T}$ cells, macrophages, and dendritic cells [11-14].

\footnotetext{
anstitute of Infectious Diseases and Molecular Medicine, University of Cape Town Medical School, Cape Town, ' NRF-DST Centre of Excellence in HIV Prevention, Centre for the AIDS Programme of Research, Durban, South Africa, 'Seattle Children's Hospital, Seattle, Washington, USA and ${ }^{d}$ National Health Laboratory Service, Cape Town, South Africa Correspondence to Jo-Ann S. Passmore, Genital Mucosal STI/HIV (GEMS) Laboratory, Division of Medical Virology, Institute of Infectious Disease and Molecular Medicine, NRF-DST Centre of Excellence in HIV Prevention at CAPRISA, University of Cape Town, Anzio Road, Observatory, 7925 Cape Town, South Africa. Tel: +27 21 6507963; fax: +27 21 4066681; e-mail: Jo-ann.Passmore@uct.ac.za
}

Curr Opin HIV AIDS 2016, 11:156-162

DOI:10.1097/COH.0000000000000232 


\section{KEY POINTS}

- Genital inflammation places women at increased risk of HIV acquisition.

- Higher levels of cytokines in the lower genital tract result in chemotaxis of highly activated HIV target cells to the mucosa.

- STIs and bacterial vaginosis are major drivers of genital inflammation.

MIP- $1 \alpha$ and MIP-1 $\beta$ are also ligands for the HIV coreceptor $\mathrm{C}-\mathrm{C}$ chemokine receptor 5 (CCR5) and specifically recruit $\mathrm{CCR}^{+}$target cells into tissues [15]. Proinflammatory cytokine signatures in the lower reproductive tract have been associated with increased frequencies of neutrophils, $\mathrm{T}$ and $\mathrm{B}$ cells, as well as higher levels of cellular activation $\left[16,17^{-"}\right]$. Proinflammatory cytokines and chemokines that are involved in activation, differentiation, and recruitment of immune cells to the genital tract may increase HIV transmission as HIV replication depends on the presence of immune cell targets, the level of immune cell activation and monocyte differentiation to macrophages or dendritic cells $[13,16]$. In rhesus macaques, proinflammatory cytokine production following vaginal simian immunodeficiency virus (SIV) exposure resulted in recruitment of $\mathrm{CD}^{+}{ }^{+} \mathrm{T}$ cells needed for establishment of SIV infection $[11,18]$. The essential role of inflammation in SIV infection was clearly demonstrated when topical application of an anti-inflammatory, glycerol-monolaurate, down-regulated chemokine concentrations, inhibited inflammatory cell influx to the genital tract, and prevented SIV infection in macaques [11].

Studies in exposed seronegative (ESN) women, who remained HIV-uninfected despite high-risk sexual activity, have improved our understanding of risk factors for HIV acquisition. In ESN women, concentrations of the CCR5-binding chemokine regulated on activation, normal $\mathrm{T}$ cell expressed and secreted were found to be elevated compared with low-risk controls, whereas MIP- $1 \alpha$ and MIP- $1 \beta$ have been shown to competitively inhibit HIV binding to CCR5 in vitro, suggesting that these chemokines may protect against HIV infection $[19,20]$. However, ESN women may have higher genital chemokine concentrations compared with low-risk controls because they are more likely to have STIs [4], and in vitro models do not account for up-regulation of other inflammatory factors or recruitment of HIV target cells by these chemokines that may facilitate HIV replication in vivo. More recent ESN studies have shown that an immune quiescent phenotype in the female genital tract may account for reduced susceptibility to HIV infection in these women [21,22]. Although ESN women were found to have higher $\mathrm{CD} 4^{+} \mathrm{T}$ cell numbers at the cervix, fewer of these cells expressed CCR5 compared with low-risk women [22].

In addition to recruiting more target cells for HIV replication, proinflammatory cytokines induce expression of the transcription factor, nuclear factor (NF)- $\kappa \mathrm{B}$, which binds to HIV-long terminal repeat and directly upregulates HIV replication [23]. Proinflammatory cytokines may also facilitate HIV infection by disrupting tight junctions between epithelial cells, reducing the integrity of this barrier [24]. In support of this, proteomic studies have shown that women with elevated genital proinflammatory cytokine concentrations have unique protein signatures of reduced epithelial barrier function [17"-]. Several proteins that regulate actin cytoskeleton organization and extracellular matrix components were found to be associated with genital inflammation, suggesting that tissue remodeling occurs in women with inflammation at the expense of effective barrier function [17"'].

\section{SYSTEMIC MARKERS OF INFLAMMATION, CHEMOKINE GRADIENTS AND HIV RISK}

Blood biomarkers have also been associated with increased risk of HIV infection $[25,26]$. Others from our group reported that women who later became HIV-infected had higher plasma concentrations of TNF- $\alpha$, IL-2, IL-7, and IL-12p70 than women who remained uninfected [25]. We found that these and other cytokines do not correlate between blood and the genital tract, suggesting that cytokine risk factors identified in blood do not predict those in the genital tract and vice versa $\left[9^{-"}, 27\right]$. Kahle et al. [26] found that elevated plasma IP-10 and IL-10 concentrations predicted HIV seroconversion in individuals in HIV discordant relationships.

ESN women had lower concentrations of HIVtarget cell recruiting chemokines, including IP-10, MIP- $1 \alpha$, and MIP-1 $\beta$, in the genital tract than blood, which may result in reduced target cell influx in the absence of a chemokine gradient to the genital tract, and thereby confer a certain degree of protection against HIV infection [21,22]. This suggests that a chemokine gradient from blood to the genital mucosa may contribute to risk for HIV infection.

The level of T-cell activation in blood appears to be important in HIV risk. $\mathrm{CD} 4^{+}$T-cell immune quiescence has shown to be protective against HIV infection in vivo [28]. Studies in European adult ESNs showed relatively lower CD38 and 
HLA-DR-expressing $\mathrm{CD}^{+} \mathrm{T}$ cells in blood than persons who go on to become HIV-infected [28]. SIVexposed sooty mangabey infants, with few peripheral and mucosal $\mathrm{CD} 4^{+} \mathrm{CCR} 5^{+}$cells, are less likely to acquire SIV via low-dose oral challenge than their rhesus macaque counterparts [29]. We found a strong correlation between peripheral and cervical T-cell activation in HIV-uninfected women [30]. Global T-cell activation may be an important contributing factor determining HIV risk.

\section{SEXUALLY TRANSMITTED INFECTIONS CAUSE GENITAL INFLAMMATION}

STIs are major causes of inflammatory cytokine upregulation and immune cell recruitment to the genital mucosa [27,31-34]. Although inflammation can be important in STI clearance, it may also cause destruction of infected epithelial layers, allowing STI-associated microbes to access deeper tissues $[35,36]$. Relatively few women are able to clear an infection in the absence of treatment, with STIs often being recurrent or persistent $[37,38]$. In addition to reproductive complications, nonulcerative STIs have been found to influence susceptibility to HIV infection $[5,8]$. We have shown that Chlamydia trachomatis, Neisseria gonorrhoeae, and Mycoplasma genitalium infections were associated with increased risk of HIV acquisition [8]. Highly prevalent STIs, such as human papillomavirus (HPV) infections, have also been shown to increase risk of HIV infection [39]. Of the common STIs, we found that Chlamydia was associated with the highest genital cytokine levels, followed by gonorrhoea, herpes simplex virus-2 (HSV-2), trichomoniasis, and bacterial vaginosis [27].

In a cohort of African women, Masese et al. [40"'] reported that the overall population risk for HIV infection was largely attributable to HSV-2, even in the absence of ulcers, with prevalent HSV-2 accounting for $48.3 \%$ and incident HSV-2 infections accounting for $4.5 \%$ of risk. Although HSV-2 ulcerative lesions disrupt the mucosal barrier, higher numbers of $\mathrm{DC}^{-S I G N}{ }^{+} \mathrm{DCs}$ and $\mathrm{CCR}^{+} \mathrm{CD}^{+} \mathrm{T}$ cells are observed in the genital tracts of women who have HSV-2, even in the absence of HSV-2 shedding or genital ulceration, and subclinical inflammatory responses in the mucosa are evident for months after a reactivation event $[34,41]$. Other infections, including yeast (6.4\%), Trichomonas vaginalis (1.1\%), $N$. gonorrhoeae $(0.9 \%)$, and nonspecific cervicitis $(0.7 \%)$, accounted collectively for $9 \%$ of the population attributable risk for HIV in an African cohort [40"']. Masese et al. [40"'] showed that prevalent HSV2 infections continued to be the most dominant population attributable risk (40.4-61.8\% between
1998 and 2012) over time. In South Africa it is estimated that over $50 \%$ of new HIV infections in women could be attributed to STIs, bacterial vaginosis and candidiasis in 2010, with HSV-2 being the most influential infection [42].

\section{BACTERIAL VAGINOSIS AND THE VAGINAL MICROBIOME INFLUENCE GENITAL INFLAMMATION}

Bacterial vaginosis is a syndrome characterized by a displacement of healthy vaginal commensal microbiota by other Gram-positive and Gram-negative bacteria $[43,44]$. A recent meta-analysis found that bacterial vaginosis was associated with 1.7-fold increased risk of HIV acquisition [7]. Masese et al. $\left[40^{-"}\right]$ reported that bacterial vaginosis contributed substantially to HIV acquisition risk, with $15.1 \%$ of the overall population risk attributable to this condition and $7.5 \%$ attributable to intermediate microbiota [40"']. Given the high infection risk and recurrence of bacterial vaginosis, this strong association with HIV risk has important public health implications.

Several studies from North America have defined a healthy female genital tract as one harboring predominantly Lactobacillus species (particularly L. crispatus and L. jensenii), having a $\mathrm{pH}$ between 3.5-4.5, having no bacterial vaginosis, candida, or other STIs [45-47], although this may not be perfectly applicable to women in Africa [47]. Recent studies from South Africa found that less than $40 \%$ of women had a vaginal microbiota dominated by Lactobacillus spp., with more than half of the women not having an easily definable predominant bacterial taxon [10"'].

Commensal microorganisms are recognized as an important component of vaginal mucosal defense against STIs [48], including HIV [49-52], but the mechanisms of this protection are not well elucidated and are likely multifactorial. There are several ways by which commensal bacteria could potentially affect vaginal inflammation and HIV susceptibility. These include: lowering vaginal $\mathrm{pH}$ as a result of their lactic acid and $\mathrm{H}_{2} \mathrm{O}_{2}$ metabolites; competitive antagonism of pathogens; antimicrobial factor production [53], modulation of epithelial barrier integrity, epithelial or immune cell function $\left[17^{-"}, 54^{\boldsymbol{\prime}}\right]$; generation of tolerizing cells such as Tregs $[55,56]$. No single bacterial strain drives all of these effects, and it is likely that more than one of these mechanisms may be at play, and may not be mutually exclusive.

In vitro experiments have demonstrated that Lactobacillus species generally induce low or no proinflammatory cytokine production by vaginal epithelial cell lines, compared with common 
bacterial vaginosis-associated organisms, such as Atopobium vaginae or Gardnerella vaginalis $[57,58]$. Anahtar et al. [10"'] found that the presence-specific combinations of noncommensal organisms (cervicotype IV defined by a high diversity of organisms, dominated by Gardnerella and Prevotella species, but also featuring Shuttleworthia, Sneathia, Megasphaera, Mobiluncus, and Atopobium) was associated with higher levels of inflammation (measured by IL- $1 \alpha$, IL-1 $\beta$, and TNF- $\alpha$ concentrations) in the genital tracts of young African women. Only half of the young women in this category had Nugent scores less than 7. Some of these noncommensal bacteria individually (Sneathia amnii, Streptococcus sanguinegens and Mobiluncus mulieris) induced inflammatory responses by vaginal epithelial cell lines [10""]. These women were followed longitudinally, and changes in prevalent cervicotypes were associated with significant increases in IL- $1 \alpha$, IL- $1 \beta$, and TNF- $\alpha$, implying a causal relationship [10"']. Other studies have found that bacterial vaginosis is associated with genital proinflammatory cytokine upregulation, but also downregulation of some cytokines $[27,59,60]$. This is likely because of the fact that bacterial vaginosis is complex, and is not the same syndrome in every case.

Proteomic analysis of women with increasing levels of vaginal dysbiosis was able to identify several cytokines and cytokine receptors that increased with bacterial vaginosis, but also found alterations in proteins associated with mucosal barrier breakdown, including mucus and cytoskeletal alterations (decreased keratins and cornified envelope proteins) [54"']. Interestingly, Arnold et al. [17"'] reported similar changes in women with increased genital inflammation, implying that bacterial vaginosis may act through these same pathways to increase susceptibility to HIV.

\section{HORMONAL CONTRACEPTIVES AND GENITAL INFLAMIMATION}

Over 50 studies have examined the association between hormonal contraceptive use and HIV. Some studies have found no association [61], whereas others have found up to two-fold higher risk of HIV acquisition in seronegative women using any hormonal contraceptive [62]. In macaques, progesterone implants increase susceptibility to vaginal inoculation with SIV [63]. This is thought to be because of epithelial thinning, which can be reversed by pretreatment with estrogen $[64,65]$. Studies of the effect of hormonal contraceptive among humans on genital epithelium did not observe the thinning seen in nonhuman primate studies [66]. Cervical ectopy, or extension of the endocervical columnar epithelium onto the ectocervix, has been associated with hormonal contraceptive use $[67,68]$. depot medroxyprogesterone acetate (DMPA) may decrease vaginal colonization by $\mathrm{H}_{2} \mathrm{O}_{2}$-producing Lactobacillus species [66]. Conversely, DMPA has been shown in cohort studies to decrease the risk of bacterial vaginosis, but to increase the risk of other STIs, including C. trachomatis and HSV-2 $[69,70]$. On a cellular level, hormonal contraceptives have been associated with cervical and vaginal inflammation [71-73], increased genital tract cellular CCR5 expression [74-76], and T-cell and macrophage mucosal trafficking [77]. Conversely, DMPA may also have antiinflammatory effects $[74,78]$.

Other possible causes of genital inflammation that may influence HIV risk include vaginal hygiene practices [79], exposure to seminal proteins [80], lubricants [81], hormone cycling [59], and genital schistosomiasis [82], as well as host genetics [83].

\section{MANAGEMENT OF SEXUALLY TRANSMITTED INFECTIONS AND BACTERIAL VAGINOSIS TO REDUCE HIV INCIDENCE}

In resource-limited settings, STIs and bacterial vaginosis are managed syndromically, according to the presence of clinical signs and symptoms [84]. However, large proportions of women who have STIs or bacterial vaginosis are asymptomatic and are thus left untreated $[8,85]$. In South Africa, the implementation of syndromic management in the mid1990s, as well as increased condom use, resulted in a decline in gonorrhoea, chancroid, and syphilis, although there has been little or no evidence of declining infection risk of other STIs and bacterial vaginosis [42]. After the introduction in South Africa, the proportion of new HIV infections attributable to curable STIs decreased from 39 to $14 \%$ between 1990 and 2010, however, the proportion of HIV infections attributable to HSV-2 increased and the contribution of bacterial vaginosis remained unchanged [42].

The results of population-wide STI treatment interventions for HIV prevention have been largely disappointing [86-90]. Two of three STI syndromic management interventions in Africa resulted in no change in HIV acquisition [91-94], suggesting that asymptomatic infections may play a significant role. We have demonstrated in South African women that asymptomatic STIs were just as inflammatory as symptomatic infections, but only $12 \%$ of women with laboratory confirmed STIs had clinical signs [8]. This suggests that women with asymptomatic infections are also at high risk of acquiring HIV. 
Treatment of HSV-2 has also been found to be ineffective at reducing HIV infection rates $[87,95]$. Although HSV-2 suppressive therapy may reduce genital ulceration, HSV-2 may induce a persistent state of susceptibility to HIV infection because of the ongoing inflammation it causes [34]. Bacterial vaginosis may also have been a significant factor contributing to the failure of these interventions, as bacterial vaginosis has proven difficult to treat, with a recurrence rate of $50 \%$ within 6 months of antibiotic treatment [96].

\section{CONCLUSION}

Although we do not fully understand the causes of genital inflammation that is associated with highHIV acquisition risk in women, prevalent STIs and bacterial vaginosis clearly play a major role. Syndromic diagnoses of these conditions are inadequate, with the vast majority of women asymptomatic. Current treatment strategies for HSV-2 and bacterial vaginosis are ineffective, with HSV-2 suppressive therapy associated with ongoing genital inflammation and antibiotic treatment of bacterial vaginosis having high recurrence rates. There is thus an urgent need for better strategies to manage STIs and bacterial vaginosis to reduce genital inflammation in women at high risk for HIV infection.

\section{Acknowledgements}

We would like to thank the CAPRISA clinical team and Professor Salim Abdool Karim for strong support with the study and conceptual input. We would also like to acknowledge the WISH clinical team, Shaun Barnabas and Smritee Dabee for help with the manuscript.

\section{Financial support and sponsorship}

The work was supported by the EDCTP Strategic Primer, Poliomyelitis Research Foundation of SA, and SA DSTNRF Centre of Excellence in HIV prevention. L.M. is a recipient of an NRF Research Career Advancement Award. Additionally we acknowledge K08HD 069201 to HBJ and RO1 RHD083040 to JAP and HBJ

\section{Conflicts of interest}

There are no conflicts of interest.

\section{REFERENCES AND RECOMMENDED READING}

Papers of particular interest, published within the annual period of review, have been highlighted as:

- of special interest

m of outstanding interest

1. UNAIDS. UNAIDS Report on the global AIDS Epidemic 2010. http://www.unaids.org/globalreport/. [Accessed 15 October 2015]
2. UNAIDS. The gap report. http://www.unaids.org/en/media/unaids/contentassets/documents/unaidspublication/2014/UNAIDS_Gap_report_en.pdf. [Accessed 15 October 2015]

3. South African Department of Health Report. The 2012 National antenatal sentinel HIV \& Herpes simplex type-2 prevalence survey in South Africa. (Department of Health, Pretoria, 2014). http://www.health-e.org.za/wpcontent/uploads/2014/05/ASHIVHerp_Report2014_22May2014.pdf. [Accessed 15 October 2015]

4. Kaul R, Ball TB, Hirbod T. Defining the genital immune correlates of protection against HIV acquisition: co-infections and other potential confounders. Sex Transm Infect 2011; 87:125e130.

5. Laga M, Manoka A, Kivuvu $M$, et al. Nonulcerative sexually transmitted diseases as risk factors for HIV-1 transmission in women: results from a cohort study. AIDS 1993; 7:95-102.

6. Taha TE, Hoover DR, Dallabetta GA, et al. Bacterial vaginosis and disturbances of vaginal flora: association with increased acquisition of HIV. AIDS 1998; 12:1699-1706.

7. Low N, Chersich MF, Schmidlin $\mathrm{K}$, et al. Intravaginal practices, bacterial vaginosis, and HIV infection in women: individual participant data metaanalysis. PLoS Med 2011; 8:e1000416.

8. Mlisana K, Naicker N, Werner L, et al. Vaginal discharge is a poor predictor of sexually transmitted infections and subclinical genital tract inflammation in women at high-risk of HIV infection. J Infect Dis 2012; 206:6-14.

9. Masson L, Passmore JAS, Liebenberg LJ, et al. Genital inflammation and the

a. risk of HIV acquisition in women. Clin Infect Dis 2015; 61:260-269.

The first study to demonstrate a relationship between elevated genital inflammatory cytokine concentrations and increased risk of HIV acquisition in vivo, suggesting that genital inflammatory responses play a crucial role in establishment of HIV infection.

10. Anahtar MN, Byrne EH, Doherty KE, et al. Cervicovaginal bacteria are a major

-1. modulator of host inflammatory responses in the female genital tract. Immunity 2015; 42:965-976.

The study comprehensively describes the relationship between high-vaginal bacterial diversity and local inflammation, providing a possible cause for the genital inflammation observed in South African women; that was associated with HIV acquisition risk. Additionally, this work describes the unique vaginal microbiome of South African women.

11. Li Q, Estes JD, Schlievert PM, et al. Glycerol monolaurate prevents mucosal SIV transmission. Nature 2009; 458:1034-1038.

12. Stanford MM, Issekutz TB. The relative activity of CXCR3 and CCR 5 ligands in T lymphocyte migration: concordant and disparate activities in vitro and in vivo. J Leukoc Biol 2003; 74:791-799.

13. Wira CR, Fahey JV, Sentman CL, et al. Innate and adaptive immunity in female genital tract: cellular responses and interactions. Immunol Rev 2005; 206:306-335.

14. Dieu-Nosjean MC, Vicari A, Lebecque $S$, et al. Regulation of dendritic cell trafficking: a process that involves the participation of selective chemokines. J Leukoc Biol 1999; 66:252-262.

15. Mueller A, Strange PG. The chemokine receptor, CCR5. Int J Biochem Cell Biol 2004; 36:35-38.

16. Nkwanyana NN, Gumbi $P$, Roberts $L$, et al. Impact of human immunodeficiency virus 1 infection and inflammation on the composition and yield of cervical mononuclear cells in the female genital tract. Immunol 2009; 128:e746-e757.

17. Arnold $\mathrm{KB}$, Burgener $\mathrm{A}$, Birse $\mathrm{K}$, et al. Increased levels of inflammatory

- cytokines in the female reproductive tract are associated with altered expression of proteases, mucosal barrier proteins, and an influx of HIV-susceptible target cells. Mucosal Immunol 2015; ePub ahead of print DOI: 10.1038/ mi.2015.51.

The study describes the proteomic profile and activation of HIV target cells that are associated with female genital tract inflammation, as well as possible mechanisms for the relationship between elevated genital inflammatory cytokine concentrations and increased HIV acquisition risk.

18. Haase AT. Early events in sexual transmission of HIV and SIV and opportunities for interventions. Annu Rev Med 2011; 62:127-139.

19. Cocchi F, DeVico AL, Garzino-Demo A, et al. Identification of RANTES, MIP$1 \alpha$, and MIP- $1 \beta$ as the major HIV-suppressive factors produced by CD8+ T cells. Science 1995; 270:1811-1815.

20. Hirbod T, Nilsson J, Andersson $S$, et al. Upregulation of interferon- $\alpha$ and RANTES in the Cervix of HIV-1-seronegative women with high-risk behavior. JAIDS 2006; 43:137-143.

21. Lajoie J, Juno J, Burgener A, et al. A distinct cytokine and chemokine profile at the genital mucosa is associated with HIV-1 protection among HIV-exposed seronegative commercial sex workers. Mucosal Immunol 2012; 5:277-287.

22. Lajoie J, Kimani $M$, Plummer FA, et al. Association of sex work with reduced activation of the mucosal immune system. J Infect Dis 2014; 210:319-329.

23. Osborn L, Kunkel S, Nabel GJ. Tumor necrosis factor-alpha and interleukin-1 stimulate the human immunodeficiency virus enhancer by activation of the nuclear factor kappa B. Proc Natl Acad Sci U S A 1989; $86: 2336-3240$.

24. Nazli A, Chan O, Dobson-Belaire WN, et al. Exposure to HIV-1 directly impairs mucosal epithelial barrier integrity allowing microbial translocation. PLoS Path 2010; 6:e1000852. 
25. Naranbhai V, Karim SSA, Altfeld M, et al. Innate immune activation enhances HIV acquisition in women, diminishing the effectiveness of tenofovir microbicide gel. J Infect Dis 2012; 206:993-1001.

26. Kahle EM, Bolton M, Hughes JP, et al. Plasma cytokine levels and risk of HIV type 1 (HIV-1) transmission and acquisition: a nested case-control study among HIV-1 - serodiscordant couples. J Infect Dis 2015; 211:1451-1460.

27. Masson $L, M$ lisana $K$, Little $F$, et al. Defining genital tract cytokine signatures of sexually transmitted infections and bacterial vaginosis in women at high risk of HIV infection: a cross-sectional study. Sex Transm Infect 2014; 90:580-587.

28. Koning FA, Otto SA, Hazenberg MD, et al. Low-level CD4+ T cell activation is associated with low susceptibility to HIV-1 infection. J Immunol 2005; 175:6117-6122.

29. Paiardini M, Cervasi B, Reyes-Aviles E, et al. Low levels of SIV infection in sooty mangabey central memory CD4 $+\mathrm{T}$ cells are associated with limited CCR5 expression. Nature Med 2011; 17:830-836

30. Jaspan HB, Liebenberg LJ, Hanekom W, et al. Immune activation in the female genital tract during HIV infection predicts mucosal CD4 depletion and HIV shedding. J Infect Dis 2011; 204:1550-1556.

31. Levine WC, Pope V, Bhoomkar A, et al. Increase in endocervical CD4 lymphocytes among women with nonulcerative sexually transmitted diseases. J Infect Dis 1998; 177:167-174.

32. Fichorova RN, Jasvantrai Desai $P$, Gibson FC, et al. Distinct proinflammatory host responses to Neisseria gonorrhoeae infection in immortalized human cervical and vaginal epithelial cells. Infect Immun 2001; 69:5840-5848.

33. Reddy BS, Rastogi $S$, Das $B$, et al. Cytokine expression pattern in the genital tract of Chlamydia trachomatis positive infertile women-implication for T-cell responses. Clin Exp Immunol 2004; 137:552-558.

34. Rebbapragada $A$, Wachihi $C$, Pettengell $C$, et al. Negative mucosal synergy between Herpes simplex type 2 and HIV in the female genital tract. AIDS 2007; 21:589-598.

35. Mcgee ZA, Jensen RL, Clemens CM, et al. Gonococcal infection of human fallopian tube mucosa in organ culture: relationship of mucosal tissue TNF- $\alpha$ concentration to sloughing of ciliated cells. Sex Transm Dis 1999; 26:160165.

36. Svanborg C, Godaly G, Hedlund M. Cytokine responses during mucosal infections: role in disease pathogenesis and host defence. Curr Opin Microbiol 1999; 2:99-105.

37. Parks KS, Dixon PB, Richey CM, et al. Spontaneous clearance of chlamydia trachomatis infection in untreated patients. Sex Transm Dis 1997; 24:229235.

38. Golden MR, Schillinger JA, Markowitz L, et al. Duration of untreated genital infections with chlamydia trachomatis: a review of the literature. Sex Transm Dis 2000; 27:329-337.

39. Houlihan CF, Larke NL, Watson-Jones D, et al. HPV infection and increased risk of HIV acquisition. A systematic review and meta-analysis. AIDS 2012; 26:10.

40. Masese L, Baeten JM, Richardson BA, et al. Changes in the contribution of

- genital tract infections to HIV acquisition among Kenyan high-risk women from 1993 to 2012. AIDS 2015; 29:1077-1085

The analysis calculated the population risk attributable of various STIs to HIV incidence, and found HSV-2 and bacterial vaginosis to be the biggest players through time.

41. Zhu J, Hladik F, Woodward A, et al. Persistence of HIV-1 receptor-positive cells after HSV-2 reactivation is a potential mechanism for increased HIV-1 acquisition. Nature Med 2009; 15:886-892.

42. Johnson LF, Dorrington RE, Bradshaw D, et al. The role of sexually transmitted infections in the evolution of the South African HIV epidemic. Trop Med Int Health 2012; 17:161-168.

43. Eschenbach DA, Davick PR, Williams BL, et al. Prevalence of hydrogen peroxide-producing Lactobacillus species in normal women and women with bacterial vaginosis. J Clin Microbiol 1989; 27:251-256.

44. Fredricks DN, Fiedler TL, Marrazzo JM. Molecular identification of bacteria associated with bacterial vaginosis. N Engl J Med 2005; 353:1899-1911.

45. Srinivasan S, Liu C, Mitchell CM, et al. Temporal variability of human vaginal bacteria and relationship with bacterial vaginosis. PLoS One 2010; 5:e10197.

46. Gajer $P$, Brotman RM, Bai G, et al. Temporal dynamics of the human vaginal microbiota. Sci Transl Med 2012; 4:132ra152.

47. Ravel J, Gajer P, Abdo Z, et al. Vaginal microbiome of reproductive-age women. Proc Natl Acad Sci U S A 2011; 108:4680-4687.

48. Spurbeck RR, Arvidson CG. Lactobacilli at the front line of defense against vaginally acquired infections. Future Microbiol 2011; 6:567-582.

49. van de Wijgert JH, Verwijs MC, Turner AN, et al. Bacterial vaginosis and vaginal yeast, but not vaginal cleansing, increase HIV-1 acquisition in African women. J AIDS 2008; 48:203-210.

50. Mirmonsef $P$, Krass $L$, Landay $A$, et al. The role of bacterial vaginosis and trichomonas in HIV transmission across the female genital tract. Current HIV Res 2012; 10:202.

51. Myer $L$, Denny $L$, Telerant $R$, et al. Bacterial vaginosis and susceptibility to HIV infection in South African women: a nested case-control study. J Infect Dis 2005; 192:1372-1380.

52. Myer L, Kuhn L, Stein ZA, et al. Intravaginal practices, bacterial vaginosis, and women's susceptibility to HIV infection: epidemiological evidence and biological mechanisms. Lancet Infect Dis 2005; 5:786-794.
53. Madan RP, Masson L, Tugetman J, et al. Innate antibacterial activity in female genital tract secretions is associated with increased risk of HIV acquisition. AIDS Res Hum Retroviruses 2015; Epub ahead of print: DOI: 10.1089/ aid.2015.0011.

54. Borgdorff $\mathrm{H}$, Gautam $\mathrm{R}$, Armstrong $\mathrm{SD}$, et al. Cervicovaginal microbiome

In dysbiosis is associated with proteome changes related to alterations of the cervicovaginal mucosal barrier. Mucosal Immunol 2015; ePub ahead of print: DOI: $10: 1038 / \mathrm{mi} .2015 .86$.

Here the authors performed targeted and unbiased proteomic analysis of women with bacterial vaginosis and provide an in depth description of host proteins that are altered in women with bacterial vaginosis and are involved in disruption of mucosal barrier

55. Atarashi K, Tanoue $T$, Shima $T$, et al. Induction of colonic regulatory $T$ cells by indigenous Clostridium species. Science 2011; 331:337-341.

56. Round JL, Mazmanian SK. Inducible Foxp3+ regulatory T-cell development by a commensal bacterium of the intestinal microbiota. Proc Natl Acad Sci U S A 2010; 107:12204-12209.

57. Libby EK, Pascal KE, Mordechai E, et al. Atopobium vaginae triggers an innate immune response in an in vitro model of bacterial vaginosis. Microbes Infect $2008 ; 10: 439-446$.

58. Doerflinger SY, Throop AL, Herbst-Kralovetz MM. Bacteria in the vaginal microbiome alter the innate immune response and barrier properties of the human vaginal epithelia in a species-specific manner. J Infect Dis 2014; 209:1989-1999.

59. Kyongo JK, Jespers V, Goovaerts $\mathrm{O}$, et al. Searching for lower female genital tract soluble and cellular biomarkers: defining levels and predictors in a cohort of healthy Caucasian women. PLoS One 2012; 7:e43951.

60. Deese J, Masson L, Miller W, et al. Injectable progestin-only contraception is associated with increased levels of pro-inflammatory cytokines in the female genital tract. Am J Reprod Immunol 2015; 74:357-367.

61. Myer L, Denny L, Wright TC, et al. Prospective study of hormonal contraception and women's risk of HIV infection in South Africa. Int J Epidemiol 2007; 36:166-174.

62. Heffron R, Donnell D, Rees $\mathrm{H}$, et al. Use of hormonal contraceptives and risk of HIV-1 transmission: a prospective cohort study. Lancet Infect Dis 2012; $12: 19-26$

63. Marx PA, Spira Al, Gettie A, et al. Progesterone implants enhance SIV vaginal transmission and early virus load. Nature Med 1996; 2:1084-1089.

64. Sodora DL, Gettie A, Miller CJ, et al. Vaginal transmission of SIV: assessing infectivity and hormonal influences in macaques inoculated with cell-free and cellassociated viral stocks. AIDS Res Hum Retroviruses 1998; 14:S119-S123.

65. Smith SM, Mefford M, Sodora D, et al. Topical estrogen protects against SIV vaginal transmission without evidence of systemic effect. AIDS 2004; 18:1637-1643.

66. Miller L, Patton DL, Meier A, et al. Depomedroxyprogesterone-induced hypoestrogenism and changes in vaginal flora and epithelium. Obstet Gynecol 2000; 96:431-439.

67. Critchlow CW, Wölner-Hanssen $P$, Eschenbach DA, et al. Determinants of cervical ectopia and of cervicitis: age, oral contraception, specific cervical infection, smoking, and douching. Am J Obstet Gynecol 1995; 173:534-543.

68. Baeten JM, Nyange PM, Richardson BA, et al. Hormonal contraception and risk of sexually transmitted disease acquisition: results from a prospective study. Am J Obstet Gynecol 2001; 185:380-385.

69. Morrison CS, Bright $P$, Wong EL, et al. Hormonal contraceptive use, cervical ectopy, and the acquisition of cervical infections. Sex Transm Dis 2004; $31: 561-567$.

70. Pettifor A, Delaney S, Kleinschmidt I, et al. Use of injectable progestin contraception and risk of STI among South African women. Contraception 2009; 80:555-560.

71. Ildgruben AK, Sjoberg IM, Hammarstrom ML. Influence of hormonal contraceptives on the immune cells and thickness of human vaginal epithelium. Obstet Gynecol 2003; 102:571-582.

72. Ghanem KG, Shah N, Klein RS, et al. Influence of sex hormones, HIV status, and concomitant sexually transmitted infection on cervicovaginal inflammation. J Infect Dis 2005; 191:358-366.

73. Chandra N, Thurman AR, Anderson S, et al. Depot medroxyprogesterone acetate increases immune cell numbers and activation markers in human vaginal mucosal tissues. AIDS Res Hum Retroviruses 2013; 29:592-601.

74. Huijbregts RP, Helton ES, Michel KG, et al. Hormonal contraception and HIV1 infection: medroxyprogesterone acetate suppresses innate and adaptive immune mechanisms. Endocrinol 2013; 154:1282-1295.

75. Prakash M, Patterson S, Kapembwa MS. Hormonal upregulation of CCR5 expression on T lymphocytes as a possible mechanism for increased HIV-1 risk. JAIDS 2005; 38:S14-S16.

76. Prakash M, Kapembwa MS, Gotch F, et al. Oral contraceptive use induces upregulation of the CCR5 chemokine receptor on CD4 $(+)$ T cells in the cervical epithelium of healthy women. J Reprod Immunol 2002; 54:117-131.

77. Zang $Y C$, Halder JB, Hong J, et al. Regulatory effects of estriol on $T$ cell migration and cytokine profile: inhibition of transcription factor NF-kappa B. J Neuroimmunol 2002; 124:106-114.

78. Ngcapu S, Masson L, Sibeko S, et al. Lower concentrations of chemotactic cytokines and soluble innate factors in the lower female genital tract associated with the use of injectable hormonal contraceptive. J Reprod Immunol $2015 ; 110: 14-21$ 
79. Scholes D, Daling JR, Stergachis A, et al. Vaginal douching as a risk factor for acute pelvic inflammatory disease. Obstet Gynecol 1993; 81:601-606.

80. Sharkey DJ, Tremellen KP, Jasper MJ, et al. Seminal fluid induces leukocyte recruitment and cytokine and chemokine mRNA expression in the human cervix after coitus. J Immunol 2012; 188:2445-2454.

81. Fichorova RN, Tucker LD, Anderson DJ. The molecular basis of nonoxynol-9induced vaginal inflammation and its possible relevance to human immunodeficiency virus type 1 transmission. J Infect Dis 2001; 184:418-428.

82. Kleppa $\mathrm{E}$, Ramsuran $\mathrm{V}$, Zulu $\mathrm{S}$, et al. Effect of female genital schistosomiasis and antischistosomal treatment on monocytes, CD4+ T-cells and CCR5 expression in the female genital tract. PLoS One 2014; 9:e98593.

83. Zabaleta J, Schneider BG, Ryckman K, et al. Ethnic differences in cytokine gene polymorphisms: potential implications for cancer development. Cancer Immunol Immunother 2008; 57:107-114.

84. World Health Organization. 2003. Guidelines for the management of sexually transmitted infections. http://www.who.int/hiv/pub/sti/en/STIGuidelines2003.pdf. [Accessed 15 October 2015]

85. Wilkinson D, Abdool Karim SS, Harrison A, et al. Unrecognized sexually transmitted infections in rural South African women: a hidden epidemic. Bull World Health Organ 1999; 77:22-28.

86. Celum $C$, Wald $A$, Hughes J, et al. Effect of aciclovir on HIV-1 acquisition in herpes simplex virus 2 seropositive women and men who have sex with men: a randomised, double-blind, placebo-controlled trial. Lancet 2008; 371:21092119.

87. Gray RH, Wawer MJ, Brookmeyer R, et al. Probability of HIV-1 transmission per coital act in monogamous, heterosexual, HIV-1-discordant couples in Rakai, Uganda. Lancet 2001; 357:1149-1153.
88. Kaul R, Kimani J, Nagelkerke NJ, et al. Monthly antibiotic chemoprophylaxis and incidence of sexually transmitted infections and HIV-1 infection in Kenyan sex workers: a randomized controlled trial. JAMA 2004; 291:2555-2562.

89. Watson-Jones $D$, Weiss HA, Rusizoka $M$, et al. Effect of herpes simplex suppression on incidence of HIV among women in Tanzania. New Engl J Med 2008; 358:1560-1571.

90. Wawer MJ, Sewankambo NK, Serwadda D, et al. Control of sexually transmitted diseases for AIDS prevention in Uganda: a randomised community trial. Lancet 1999; 353:525-535.

91. Grosskurth $H$, Todd J, Mwijarubi $E$, et al. Impact of improved treatment of sexually transmitted diseases on HIV infection in rural Tanzania: randomised controlled trial. Lancet 1995; 346:530-536.

92. Grosskurth $\mathrm{H}$, Gray R, Hayes R, et al. Control of sexually transmitted diseases for HIV-1 prevention: understanding the implications of the Mwanza and Rakai trials. Lancet 2000; 355:1981-1987.

93. Gregson $\mathrm{S}$, Adamson S, Papaya S, et al. Impact and process evaluation of integrated community and clinic-based HIV-1 control: a cluster-randomised trial in eastern Zimbabwe. PLoS Med 2007; 4:e102.

94. Kamali A, Quigley $M$, Nakiyingi J, et al. Syndromic management of sexuallytransmitted infections and behaviour change interventions on transmission of HIV-1 in rural Uganda: a community randomised trial. Lancet 2003; $361: 645-652$.

95. Barnabas RV, Celum C. Infectious co-factors in HIV-1 transmission herpes simplex virus type-2 and HIV-1: new insights and interventions. Current HIV research 2012; 10:228.

96. Barrons R, Tassone D. Use of Lactobacillus probiotics for bacterial genitourinary infections in women: a review. Clin Ther 2008; 30:453-468. 